\title{
'Body as a Machine': How Adolescents with Sickle Cell Disease Construct Their Fatigue Experiences
}

\author{
Brenda Agyeiwaa Poku \\ University of Nottingham, UK \\ Ann-Louise Caress \\ University of Huddersfield, Huddersfield, UK \\ Susan Kirk \\ University of Manchester, Manchester, UK
}

Dr Brenda Agyeiwaa Poku, PhD MSc, BNurs, School of Health Sciences, University of Nottingham, Nottingham, Derby Road, NG7 2HA UK

Professor Ann-Louise Caress, PhD, BNurs, RGN, RHV, DN Cert, Department of Nursing and Midwifery, School of Human and Health Sciences, University of Huddersfield, Huddersfield, HD1 3DH, UK

Professor Susan Kirk, PhD, MSc, BNurs, RGN, RM, RHV, DN Cert, Division of Nursing, Midwifery and Social Work, School of Health Sciences, Faculty of Biology, Medicine and Health, University of Manchester, Oxford Road, Manchester, M13 9PL, UK

Brenda Agyeiwaa Poku is a postdoctoral research fellow and a member of the children and young people health research (CYP-HR) group at the University of Nottingham, with keen interest in the life experiences and self-management practices of children and young people with chronic illnesses.

Ann-Louise Caress is a professor of nursing and health service research with interest in living with and management of long-term conditions, using a range of research methods, particularly qualitative approaches.

Susan Kirk is a professor of family and child health whose research examines the lived experiences of childhood longterm and life-limiting conditions including self-care, service support and transition to adulthood. 


\begin{abstract}
Research exploring illness experiences of young people with sickle cell disease (SCD) has, to date, ignored fatigue, despite the distinctive anemic nature of SCD. To examine adolescents with SCD fatigue experiences, we conducted narrative and picture-elicitation interviews with 24 adolescents in Ghana. A grounded theory, 'body as a machine' was constructed from the narratives. Fatigue represented the most restrictive and disruptive aspect of growing up with SCD. Its meaning and significance laid in what it symbolized. Fatigue represented a socially undesirable feature that was stigmatizing, due to the expectations of high physicality in adolescence. Fatigue was therefore a major threat to 'normalcy'. The social significance of the physical body and its capacities shaped the adolescents' fatigue experiences. Managing fatigue to construct/maintain socially acceptable identities dominated the adolescents' lives. Consequently, there is a need for a recognition of the significance of fatigue to adequately support young people growing up with SCD.
\end{abstract}

\title{
Keywords
}

adolescent; body; children; constructivist grounded theory, experiences; fatigue; Ghana; qualitative research; self-management; sickle cell disease; young people; youth 


\section{Introduction}

Sickle cell disease (SCD) is the most prevalent and fastest-growing heritable pediatric blood disorder globally, which affects children of African, Mediterranean, Middle Eastern and South Asian descent (Piel et al., 2013). Globally, an estimated number of 300,000 live babies are born annually with the condition, with $75 \%$ of these births occurring in sub-Sahara Africa (Piel et al., 2013). In developed countries like the USA, SCD occurs in 1 in 500 African American live births annually (National Heart, Lung and Blood Institute, 2009), while in the UK, SCD affects about 14,000 people (Dormandy et al. 2018).

SCD is characterized by life-limiting and life-threatening complications such as chronic anemia, acute and severe pains, delayed growth/sexual development, increased vulnerability to severe infections and stroke, leading to significant morbidity, psychosocial and economic impacts (Mulumba \& Wilson, 2015). A recent integrative review of adolescents' experiences of living with SCD highlighted how SCD impacts negatively on adolescents' physical functioning, social relationships, emotional well-being, self-concept, social identity, and schooling (Poku, Caress \& Kirk, 2018). Among the many SCD-related symptoms, pain was the most explored.

Although the distinctive chronic hemolytic anemia, inflammation and pain that characterize SCD suggests that individuals with the condition are at risk of experiencing substantial fatigue, fatigue is under-explored and not prioritized in research and clinical care compared to SCD-related pain (Poku et al., 2018). This lack of attention may be due to the nihilistic perceptions that fatigue is an inevitable consequence of the condition, about which nothing can be done and therefore must be endured by those living with SCD (While \& Mullen, 2004). Nonetheless, the limited research into how adolescents with SCD experience fatigue has identified a number of ways fatigue impacts on adolescents, including reduced health-related quality of life, increased pain episodes, depressive and anxiety symptoms, 
reduced physical, social and cognitive function, and frequent school absence (Dampier et al., 2010; Amr, Amin \& Al-Omair, 2011; Ameringer, Elswick \& Smith, 2014; Panepinto et al., 2014; Anderson et al., 2015; Rogers \& Lance, 2017). While such findings highlight the presence and impact of fatigue on adolescents, studies predominately adopted a more clinical perspective to examining fatigue, using assessment tools to explore a very subjective symptom. Consequently, little is known from adolescents' own narratives about how they experience fatigue, as well as the implications of their socio-cultural context on their fatigue experiences.

For adolescents, in particular, an in-depth understanding of fatigue is of paramount importance. Adolescence is a period of transition, where children are confronted with the challenges of growing up and negotiating emerging social responsibilities, expectations and demands and therefore may be significantly vulnerable to the effects of fatigue (Ameringer et al., 2014). The aim of the study was to fill this knowledge gap and widen the current knowledge base about fatigue in adolescents with SCD by exploring in-depth how they experience and manage fatigue on a day-to-day basis.

The study was conducted in Ghana, where SCD affects $2 \%$ of all newborns annually (Ohene-Frempong et al., 2008). Although SCD is a genetic condition, the cause of the illness held by some lay people in Ghana lie within the supernatural world (Dennis-Antwi et al., 2011). Therefore, children with SCD and their families are reported to contend with victimization, ridiculing, labelling and isolation (Dennis-Antwi et al., 2011). This causes children with SCD and their families to strive to conform to societal expectations regarding parenthood and childhood/adolescence in order to keep the condition a secret from society. Within the Ghanaian traditional value system, a child's perceived fundamental role is perpetuating family/cultural mores (Boakye-Boaten, 2010). Therefore, socialization and parenting aim to enculture children in the 'Ghanaian way' for adulthood (Salm \& Falola, 
2002). Societal norms, values, statuses and roles are imparted primarily through task allocation, and personhood is only acquired during functional maturation (Salm \& Falola, 2002). Given this, it is commonplace for children, from a young age, to be seen participating in household and school chores, and other minor economic activities (Boakye-Boaten, 2010).

Thus, a child's sociocultural development is mainly based on the values attributed to physical work. Gender and age influence task/chore allocations and the expected level of participation. Girls are trained to take up domestic roles, as preparation towards future gendered roles, whereas boys' training emphasizes leadership, competitiveness and physical/emotional strength (Salm \& Falola, 2002). Children's cultural responsibilities increase as they grow older. They begin doing physically easy tasks, and gradually the level of difficulty/skills increase with their age, based on the assumption that children's physical strength/competence naturally increases with age (Chant \& Jones, 2005). Consequently, a high level of activity, performance and participation is expected of all adolescents regarding their assigned tasks. Being physically active and energetic is perceived as a central characteristic of youthfulness, and high physicality and industriousness are highly valued and encouraged in adolescence (Salm \& Falola, 2002).

\section{Method}

We chose the grounded theory approach to help elicit and make sense of adolescents' fatigue experiences, and produce an explanatory grounded theory. Due to the lack of research about the subjective fatigue experiences of adolescents with SCD and their self-management strategies, we decided to co-construct their experiences with them. Grounded theory approach is best suited for exploring previously little-researched phenomenon and co-constructing knowledge (Birks \& Mills, 2015). Moreover, this methodological approach is most appropriate when a study aims to generate a theory with explanatory power, as well as 
discover the social processes in the research situation (Birks \& Mills, 2015), which constituted the study objectives. In addition the approach has been used by others undertaking research with adolescents (Laird, Fawkner \& Niven, 2018). Acknowledging that knowledge is both socially constructed and situated and that we come to know by constructing our understanding of reality through social interactions with others, we adopted Charmaz's constructivist grounded theory approach (Charmaz, 2014). Following the constructivist approach, we acknowledged that our prior perspectives and the existing literature would guide the research (Abrams \& Curran, 2011). All authors have a nursing disciplinary background. Susan Kirk is an expert qualitative researcher in children and young people living with chronic conditions.

\section{Recruitment and sampling}

We recruited from two SCD clinics in Ghana. Participants were eligible for participation if they were aged 12-17 years; had no other comorbidities or were not pregnant (to ensure that the data generated related to SCD because fatigue is known to be associated with many illnesses and pregnancy); and could communicate effectively in the English or Twi languages, the most common spoken languages in Ghana, both of which Brenda Poku is fluent in. Clinicians at the clinics introduced the study to eligible adolescents and their parents. Those who expressed interest in the study were introduced to Brenda Poku, who provided them with detailed information about the research and what their involvement would entail. Each had the opportunity to ask questions before deciding to participate, and those who expressed interest were given two days after the initial contact with the researcher to reflect on the study and consider taking part. After the 48 hours, the researcher phoned them to find out about their decision and answer any further questions they may have. At this 
point, verbal assent and consent were taken from both the adolescent and a parent, respectively, and the place and time for an interview was negotiated with them.

Initially, participants were purposively sampled to ensure maximum variation in relation to gender, age, place of residence, ethnicity, educational level, and family socioeconomic background. As the study progressed, theoretical sampling based on the categories emerging from data analysis was incorporated to seek out data for conceptual and theoretical development of the analysis (Charmaz, 2014). Theoretical sampling did not lead to seeking out participants of specific characteristics but instead guided the issues to pursue in later interviews. Sample characteristics are reported in Supplemental Table 1. All the adolescents were clinically stable; none of them had additional health-related conditions or was pregnant.

\section{Data collection}

We intended to let the adolescents convey their thoughts as capable social actors (Kellet \& Ding, 2004). Consequently, we adopted a range of methods. We used traditional interviews, drawings, photography and picture-elicitation. Multi-method and art-based designs have been shown to be particularly effective in research with adolescents, empowering them and making participation in research more interesting by providing them greater flexibility in how they choose to represent their experiences, as well as allowing for different, but complementary, insights into the meaning they make of their worlds (Poku, Caress \& Kirk, 2019). Thus, we allowed adolescents to decide the extent of their participation and how and what they used to communicate their experiences. By giving the adolescents the opportunity to produce images that spoke to their own experiences in combination with in-depth interviewing, we aimed to enable them construct narratives about their fatigue experiences. Fifteen adolescents participated in the traditional interviews, and nine participated in the picture-elicitation interviews. 
The traditional interviews lasted on average one hour, whereas in the pictureelicitation interviews, the images elicited more extended conversations, lasting an average of two hours. Because the picture-elicitation interviews required prior-reflection, which initiated a degree of self-interpretations of experiences by the adolescents prior to the interviews, they generated richer narratives. In addition, the discussions of the images created deeper insights, resulting in rich data that were only accessible through the images, as well as helping to make sense of some of the data generated from the traditional interviews (Poku et al., 2019).

Just before a scheduled interview began, which took place either at participant's home, school, clinic or parent's workplace, depending on their preferences, the researcher discussed again the purpose of the research and what was involved and whether they still wished to take part. At this point, written assent from the adolescents and consent from a parent were taken before the interview was conducted. All interviews were conducted privately with the adolescents, except two where parents insisted on observing the interaction. The interviews were conducted as flexible, semi-structured conversations between November 2016 and June 2017. They were guided by an interview guide, as well as participantproduced images in the picture-elicitation interviews. The interview guide consisted of a series of prompts related to topics such as definition/description of fatigue, consequences of fatigue, management of fatigue and this was revised as new ideas emerged from the interviews. As the study progressed, the guide evolved into an aide-memoire list of four main topic areas: the representation of fatigue; the sociocultural issues significant to fatigue experiences; the interaction between fatigue and daily functioning, identity, and social relationships; and the interactions between fatigue, identity and self-management decisions/choices. Interviews were conducted in English and/or Twi, the two commonest languages spoken in Ghana. With permission, the interviews were audio-recorded, fully transcribed, and translated into English where necessary by Brenda Poku. Consent was 
sought to use the interview excerpts and images anonymously during the research dissemination.

\section{Data analysis}

Interview transcripts and images were anonymized, using pseudonyms chosen by the adolescents, and imported into NVivo $11^{\mathrm{PRO}}$ to organize and manage the data. Using the grounded theory approach, data were analyzed iteratively through line-by-line, focused and theoretical coding, and constant comparison to identify analytical categories (Charmaz, 2014). Attention was paid to concepts that explicated how the adolescents responded to their fatigue, the meaning they held towards those actions and their fatigue, and how those actions and meanings interacted and evolved (Charmaz, 2014). Informal memos were written, and diagrams were drawn to develop ideas about the data and visualize connections between the categories. Sampling continued until all the dimensions of the theoretical categories were adequately developed, and no new insights were apparent. The authors met regularly during data collection and analysis to discuss the codes, categories, relationships and interpretations being made to ensure the authenticity of the findings generated. Data were analyzed in the English language.

\section{Rigor}

The principles of grounded theory by Charmaz (2014) highlighted above were applied to ensure rigor in the conduct of the study and the interpretation of the outcomes. We employed (a) multimethod data collection approaches and recruited from two settings to ensure comprehensiveness and credibility of the data generated; (b) purposive and theoretical sampling to ensure variation in the sample and data; (c) line-by-line coding, constant comparison, searching for deviant cases, and memo-writing to maintain the trustworthiness 
and authenticity of the data generated; and (d) theoretical sensitivity to stimulate reflection on the data. These critical approaches allowed us to construct from the data a theory that fulfil the criteria for high-quality grounded theory research set by Charmaz (2014): originality, credibility, resonance and usefulness. We acknowledged that data and analysis are coconstructed by the researchers and participants, who bring their ideas, experiences, views and interactions to shape the research process and outcomes (Charmaz, 2014). In view of this, we took a reflexive stance by thinking critically about our experiences and assumptions, which include both clinical and nonclinical expertise and knowledge and how these might have shaped the research (Markham, 2017).

\section{Ethical issues}

Three ethical review committees granted ethical approval for the study (16435, CHRPWE/AP/462/16, and KBTH/MD/G3/17). In Ghana, parents have the absolute power to make decisions on behalf of their children up to 18 years. To conform to this cultural requirement while acknowledging the international legislation on children's rights, informed consent was considered a family decision. Only participants who willingly assented and whose parents provided consent were interviewed. They were guaranteed of their right to withdraw from the study at any time, as well as withdraw their images. Attention was paid to participants' behaviors during the interviews to remain sensitive about their voluntary participation. Arrangements were made with the clinics to provide post-interview emotional support to participants who became acutely distressed, and to manage any disclosures of harm. Power differential was managed by using visual methods to give the adolescents an active role in the research (Poku et al., 2019); adopting a less adult-centric appearance (Epstein, 1998), giving participants' choice over the interview schedule and control of 
interview recording (Moore, McArthur \& Noble-Carr, 2008); and adopting relationality and reciprocity (Hall \& Callery, 2001).

\section{Findings}

The theory is comprised of a core category, 'body as a machine' and two inter-related subcategories ('losing the energy' and 'managing the energy'). It represents the adolescents understanding of and the meaning they assigned to their fatigue; the contributory factors and consequences of fatigue; and the strategies they employed to self-manage fatigue. The components making up the theory are represented diagrammatically in Figure 1. The theory depicts how adolescents with SCD experienced fatigue through a process of 'losing the energy' and 'managing the energy' on a day-to-day basis, which was influenced by social constructions regarding childhood, youthfulness, adulthood, identity and normality.

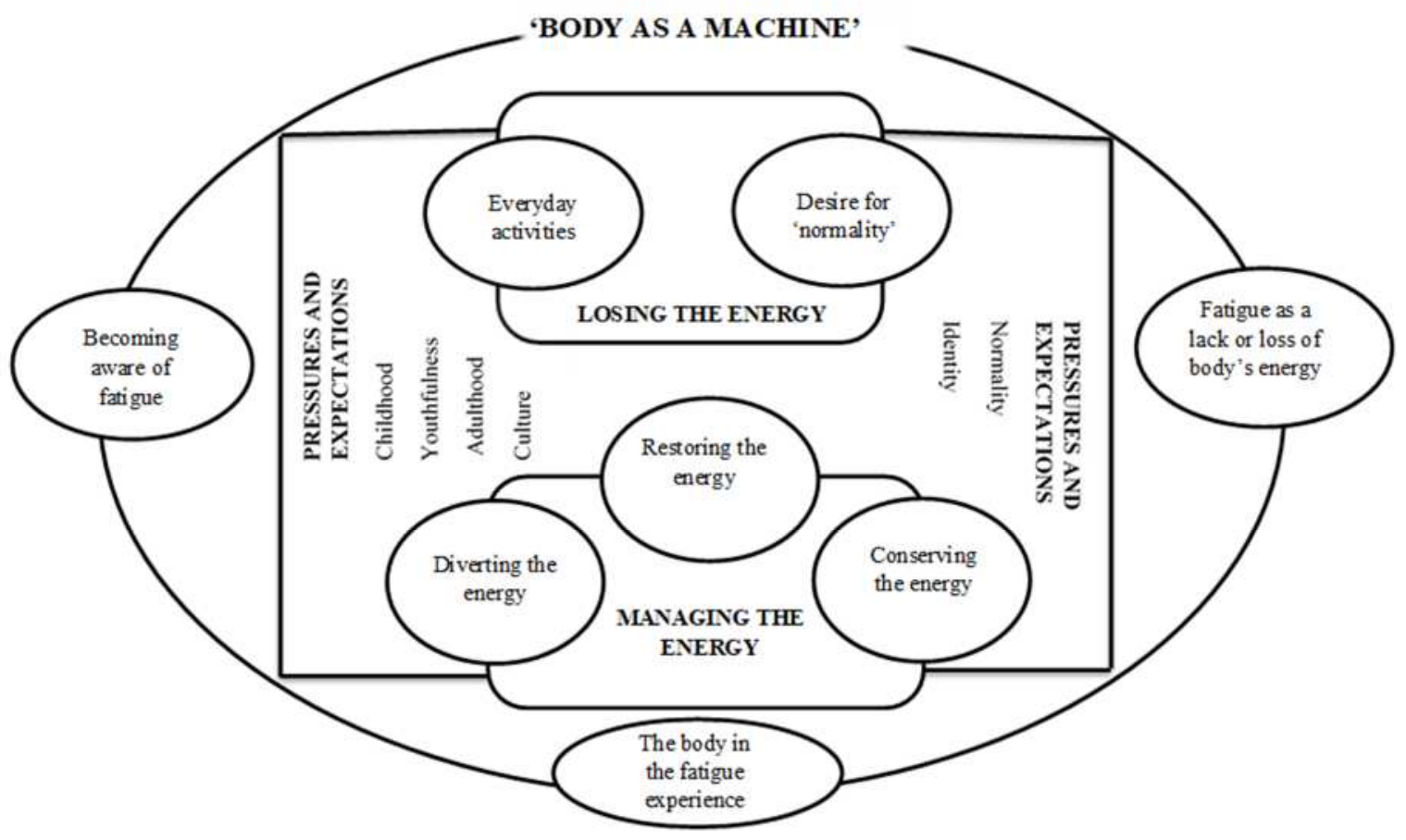

Figure 1: The Body as a Machine theory 


\section{'Body as a machine': meaning and construction of fatigue}

All the participants conceptualized their fatigue as a bodily experience. All perceived the body as a machine, and fatigue was tied to its energy and performance capacity. For instance, one participant exemplified fatigue as depletion or loss of a car's energy:

It's (tiredness) like a car with no petrol. Nothing will make it move. (Adolescent male, 14 years)

The' body as a machine' analogy was used by the adolescents to comprehend, shape their understanding of and communicate their fatigue experiences. The participants conceptualized their own bodies (which some participants explicitly described as the 'SCD body') as machines with limited energy capacity, which it loses quickly, and defined the fatigue they experienced as a state of energy loss or depletion. One young person highlighted this conception by linking the SCD body capacity to a USB drive with a limited storage capacity:

My body is like a 64MB drive. I mean it has a very little energy capacity due to sickle cell; therefore, the energy drains very fast. I never have enough for the things I want and need to do. (Adolescent male, 16 years)

Fatigue was perceived as a dysfunction of the SCD body. This perception identified fatigue as an embodied experience, something lived and experienced in the body, and not merely a medical symptom. Fatigue as a dysfunction of the biological body also heightened the adolescents' awareness of their own embodiment by separating the self and the body. However, this awareness did not suggest a dualistic view of the self and the body, but instead, 
made the adolescents aware of a connection and interdependency between the self and the body. In explaining this interdependency, one adolescent likened the body to an electricity meter (Figure 2), which used energy credit on a pre-paid card (Figure 3) to power electrical gadgets/self. She explained how when there is energy depletion/fatigue, the meter/body is unable to support the function of the gadgets/self:

The pre-paid meter stands for my body, the pre-paid card represents my energy storehouse, and the credit represents the energy available to use. If there's no credit or it gets used up, there won't be any electricity to power the lights, ceiling fan and TV. Everything becomes useless, me and the body. (Adolescent female, 17 years)

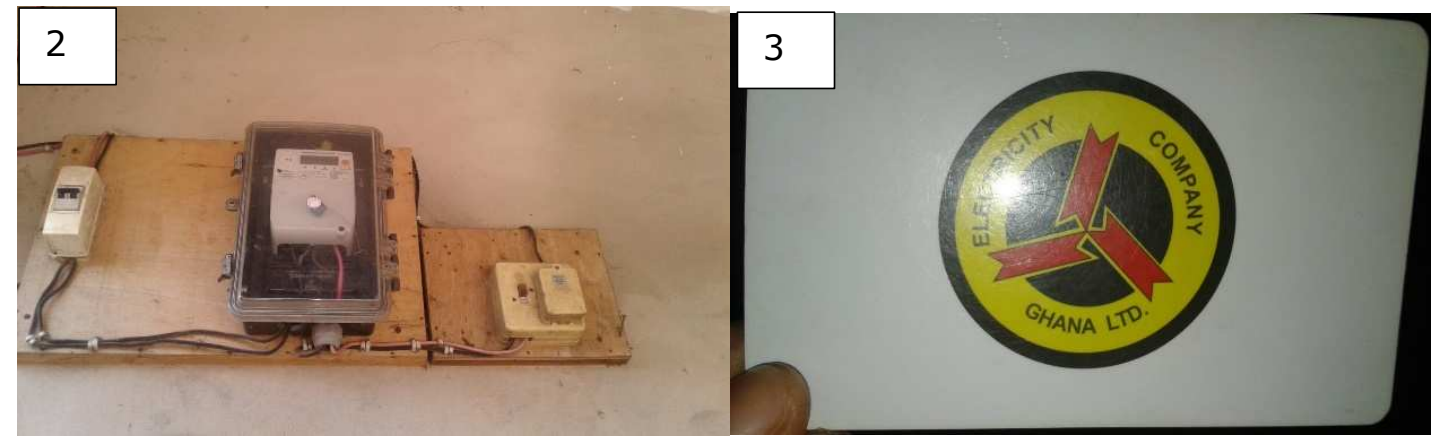

Figures 2-3: Electricity meter and a pre-paid card (Adolescent female, 17 years)

Although the SCD body was likened to a machine, it was not perceived by the adolescents as passive, but rather as an active and a reactive entity due to its limitations. The SCD body was perceived to monitor energy usage by setting limits and boundaries and restricting activities to avoid fatigue. One adolescent described a dialogical relationship between the self and the SCD body. He explained how the SCD used physical symptoms such as increased heart and breathing rates, light-headedness and pains to communicate signals of energy consumption and imminent energy depletion to the self. It was important 
for the self to hear, comprehend and give attention to these signs. According him, it was important for him to 'listen' to and stay 'in tune' with his body:

I know when I'm about to get tired. I start panting small small and my breathing increases. When that happens, I stop playing. That way, I don't get too weak. (Adolescent male, aged 13)

Fatigue appeared to result when this dialogical body-self relationship is not maintained. The SCD body was described to be unyielding and relentless in the relationship, having greater control and influence over the self. It could not be controlled and bent to the wishes of the self; rather, it constrained the self. Its reduced biological capacity impinged on the self and acted as a limiting factor on the adolescents' daily functioning:

When I'm playing with my friends or when I'm walking, and I start feeling my heart beating fast, and I'm breathing quickly, it means I'm gradually using petrol in the car. If I continue, my heart pounds faster, breathing become faster and I start to feel some pains, it means my body is telling me that my energy is about to get finished, so I need to do something fast. If I don't stop and rest but continue, I'll start feeling dizzy, and the pains become very severe, which forces me to stop. (Adolescent male, 14 years)

From the adolescents' narratives, the body-self relationship, in the context of fatigue, appeared to be complex and changing. Sometimes there was a dialogical or reciprocal relationship (when the young people listened to the body and acknowledged its power), and 
sometimes there is a sense that they were in conflict or opposition (when the young people overlooked or ignore the body and its power).

\section{'Losing the energy': contributory factors and consequences of fatigue}

The adolescents' understandings of a socially acceptable adolescent body and their desire to conform to this disrupted the body-self relationship and led to fatigue. The adolescents believed that being physically active, demonstrating immense energy and performance capacity, and having high levels of endurance and tolerance were the 'normal' characteristics of adolescence/youthfulness. These bodily expectations created a reality as well as a reference point or an image of what a 'normal' adolescent body was for them. From their perspectives, these bodily attributes were of a high symbolic value culturally and constituted inflexible social expectations that accompanied every activity, congruent to their gender that they undertook. Thus, any adolescent body lacking these attributes, like the SCD body was disapproved of and perceived as inferior and of lower symbolic value, hence, running the risk of being stigmatized. This was an understanding they have acquired through their socialization. This perceived image of a 'normal' adolescent body influenced how the participants related to their bodies and consequently, how they experienced fatigue. It made it difficult for them to stay in tune with the SCD body, by forcing them regularly to push it beyond its capacity, which disrupted the body-self relationship and led to frequent experience of extreme fatigue. One adolescent narrated how he pushed himself regularly when engaged in any activity to meet these social expectations:

You know, everyone expects you to be strong and not get tired easily as a young person. This makes me ignore my body and force myself to do things, causing painful tiredness. (Adolescent male, aged 14 years) 
The incapacities of the SCD body were invisible to others until the adolescents became fatigued. According to one female participant and one male participant, their fatigue was discredited and construed as incompetence, laziness and weakness within their social domains due to their age and normative appearance. The negative social reactions to their fatigue were gendered. The young male was labelled as being weak and the young female as being lazy. This gendered labelling was influenced by the culturally defined characteristics of masculinity (i.e. virility, power, strength, and athleticism) and femininity (i.e. domestic industriousness) in the Ghanaian society (Salm and Falola, 2002). The perceived need to perform activities to the socially-expected level congruent with their age and gender in order to avoid social stigma made them constantly conscious of their social performances, and determined and regulated how they wished to use and present their bodies:

When I get tired, they ridicule me that I'm lazy. They see you as normal, you know, you're not disabled so why should you get tired easily or why can't you do this or that. When someone meets you, they can't tell you get tired easily, so they expect you to be normal. So, I tend to force myself even when I'm tired. As you know, when you push yourself, you shut down eventually. (Adolescent female, 13 years)

It makes me feel bad because he [friend] tease me that I'm weak, incompetent and there's no fun in playing sporty games with me because I'm always complaining that I'm tired, so, I keep pushing myself (Adolescent male, 14 years)

The 'body as a machine' image as well as the internalized perception about youthfulness helped the adolescents to interpret the social reactions to their bodies and fatigue. The adolescents appeared to have developed and constructed the image through their 
social relations, stemming from shared sociocultural conception and interpersonal ideas about youthfulness within their social domains. The image and its associated social expectations also enabled the participants to link the diminished capacity of the SCD body to the concepts of self and identity. The participants based their perceived self-esteem, self-worth, selfidentity and sense of 'normality' on the ability to perform activities in line with the cultural expectations. Consequently, there was an active pursuit to separate fatigue (which represents the biological deficiency of the SCD body) from their sense of normalcy. Presenting the SCD body as an efficient machine was crucial for the presentation of the self as 'normal' in the adolescents' everyday lives. Indeed, one young person expressed a sense of pride in keeping up with activities at all cost despite the consequences on his health:

Being able to push myself to do things as a young person makes me happy even when I end up with severe painful tiredness. It makes me feel like everyone else and relevant. (Adolescent male, 16 years)

Paradoxically, however, keeping up with activities at all cost sometimes undermined attempts to present the self as 'normal' due to the limits imposed by the SCD body as this data extract illustrates:

One time at school, I overexerted myself and had a blackout. When I woke up, everyone was around me, having a look like there's something abnormal about me, like epilepsy or something. I couldn't stand that they may be thinking that way because no one in school knows that I've sickle cell. They saw me as normal until that time. I felt embarrassed. (Adolescent female, 14 years) 
The control and influence the SCD body had over the self led most of the adolescents to accept their bodies as inferior through an active, intentional process of surrendering to it. This acceptance influenced their perceived self- identity, self-labelling themselves as the boy who gets tired easily and always, the guy who doesn't have enough energy to do the things he wants, the weak guy, and the lazy girl. This resignation motivated them to develop selfmanagement strategies to enable them to stay in tune with the SCD body to balance the bodyself relationship to control fatigue.

\section{'Managing the energy': self-management of fatigue to construct a socially acceptable identity}

The adolescents' fatigue self-management was aimed at managing the SCD body's limited energy to prevent its incapacities from being discerned and stigmatized in order to present a 'normal' self. The 'body as a machine' perception created the ideal image, which guided the management strategies. The strategies employed were based on actively managing limited energy resources to ensure the SCD body worked as efficiently as possible. Energy management was conceptualized as a mechanical process, with strategies based on energy restoration, conservation and diversion.

Energy restoration was aimed at maintaining the SCD body's energy daily. The participants perceived the body to require fuel in the form of food to function. Using phrases such as fill the tank before activities and top up during activities, one participant conveyed that eating healthily and regularly was a way of maintaining the SCD body's energy stores. This was done to ensure constant availability of energy to maintain performance capacity in order to ward off fatigue, to present the SCD body as an efficient machine, and consequently present the self as 'normal': 
Before the ceremony, I ate a heavy meal so I'll have enough energy for the procession. I had a full tank. I constantly drank glucose water during the procession to top up my energy. This helped me to take part in the procession for long before feeling tired. (Adolescent female, 13 years)

Energy restoration also involved measures to replenish the SCD body's energy when drained by an activity. Rest and hydration were the commonest and most successful measures employed. All the adolescents explained how these strategies enabled them to rejuvenate their energy:

The water I drink and the rest is like buying some credit onto the pre-paid card to run the meter. So, it's like me replenishing my energy storehouse to run my body. (Adolescent female, 17 years)

The adolescents made daily efforts to rest in isolation in an attempt to hide the SCD body's performance incapacities, which become visible when fatigued, in order to pass as 'normal' and maintain their preferred social identity. The fatigued SCD body was removed to hide it from suspicions of incompetence, laziness and weakness. One young person's perspective was typical:

It's very important that you've somewhere to go to when you're tired, be on your own and shut off everybody and everything to deal with it (tiredness). People treat you bad when they see you tired. So, when I'm tired, I'm in a hurry to get to my room. (Adolescent male, 13 years) 


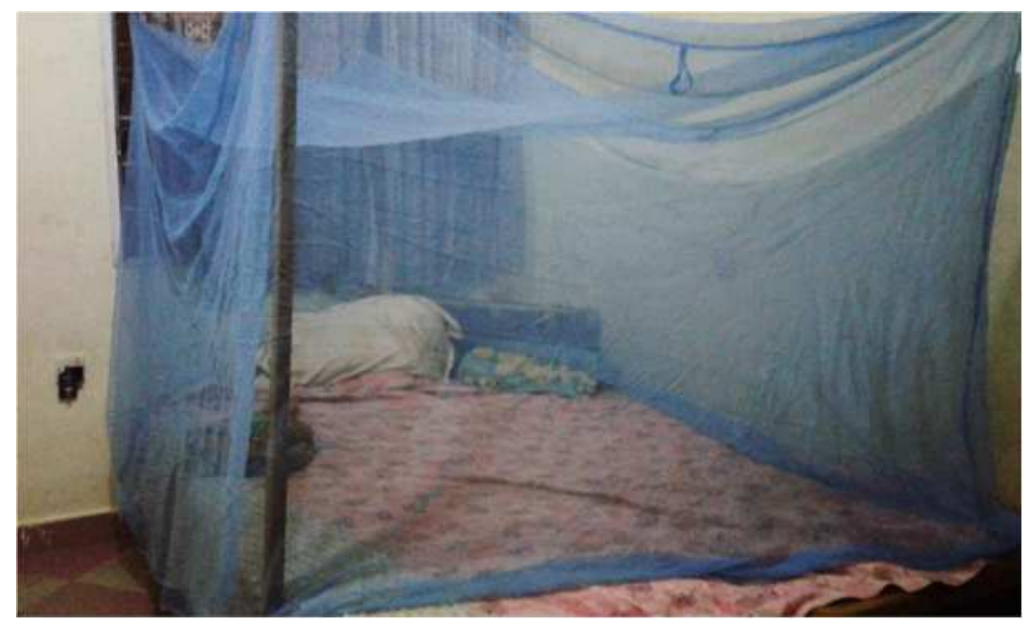

Figure 4: An adolescent male aged 13 years bedroom

One participant explained how she developed plausible explanations for removing herself from social situations to reduce the risk of revealing the fatigued SCD body to avoid being stigmatized. Such attempts at impression management appeared to be her way of concealing the SCD body and its limited capacity to pass as 'normal' to maintain a desired social identity:

To avoid the hurtful words, when I get tired, I don't tell them [friends]. I make an excuse and leave for the house to rest. I tell them I have to run some errands for my mum or go and check on my little siblings. (Adolescent female, 14 years)

The second strategy, energy conservation was a common energy management strategy the adolescents used to stay in tune with the SCD body on a daily basis. They conserved their limited energy through activity pacing, either by avoiding or reducing activities that they felt contributed to their fatigue. While these conservation measures enabled them to maintain a stable body-self relationship, they encouraged social isolation and withdrawal and failed to support the adolescents' desire to present a socially acceptable self. In order to avoid this, selectively prioritizing certain social activities and investing the limited energy into them was 
how some of the participants attempted to present themselves as 'normal' at certain times and within certain social spaces as they paced themselves daily. Some participants 'played to their strengths' by assigning higher priority to nonphysical activities over physically-demanding activities to efficiently preserve their limited energy and construct a positive social image. One adolescent explained how he prioritized and engaged in activities in which he excelled:

I sit and draw instead of play games and run during PE. That way I don't use so much energy so I won't get tired. When my friends are playing, instead of joining them, I just sit and draw them; and I show it to them afterwards. My friends like me for my drawings. I'm popular because of that. (Adolescent male, 12 years)

As the adolescent's account indicates, this approach resulted in a downward shift in identity for the male adolescents, as they had to relinquish athleticism associated with the masculine identity. Nonetheless, when the benefits of relinquishing physical activities exceeded the relative costs, they appeared to be content with giving up 'valued' identities:

I'm very good at drawing, and I'm popular because of it, but it's not like being physically active and fit. But I'm ok with it because it saves me from getting very tired and ending up with pains and missing school. (Adolescent male, 12 years)

Other participants also tried to project a 'normal' self by prioritizing and bracketing their social engagements to times such as school trips and football tournaments when significant people they wished to present themselves to as 'normal' were present:

But when I know an activity like a football competition is very crucial for me to show them that I'm normal and not weak, I push myself and engage in it till the point I 
can't anymore. By then I'll have shown myself as strong and capable. Afterwards, I'll deal with the overwhelming tiredness privately. (Adolescent male, 16 years)

Finally, energy diversion was a strategy employed by some participants to reduce or evade the perceived inflexible social expectations of the adolescent body that pressurized them into depleting their energy in order to present a 'normal' identity. It involved them diverting their limited energy into intellectual pursuits, which they perceived as highly regarded in their social domains. They perceived intellectual work to require and demand less energy and to be a socially acceptable alternative to physical activeness. The adolescents made this intellectual investment at the expense of their social interactions and relationships. From one young person's accounts, this approach to energy management not only helped him to reduce people's expectations of him, regarding the acceptable bodily performance, but it also enabled him to create a credible self and present a socially valued identity:

Because I know academic work is not as hard as those physical activities, I focus my energy on them so I can avoid tiredness. My granny and teachers are happy when they see me learning instead of playing football or roaming about with my friends. Focusing on my studies is helping me prove that I'm not weak or lazy or incompetent, so, I divert all my little energy and strength to my academics. I use every opportunity to study. As you know, doing well in school is even more important than all those physical strengths because, in the future, being intellectual will make you more prominent than the physical prowess. (Adolescent male, 15 years)

As the young person's account indicates, contrary to the notion of linking normality in adolescence to the perceived bodily attributes of a youthful body, they connected normality in 
adulthood to career and family successes. This notwithstanding, the young person referred to the potential of fatigue to upset their ability to assume positive identities. Thinking in terms of risk forced him to seek to shape and stabilize his future towards his desired outcome. Therefore, deciding to invest the limited energy into intellectual pursuit was a presentoriented fatigue management strategy connected and geared towards the future. The adolescents who employed this strategy were consequently 'living for the future', believing their fatigue-centered self-management strategies in the present will, at the very least, have a bearing on who they become in the future. This energy management strategy, compared to the others was the single strategy that enabled the adolescents who employed it to use their limited energy efficiently, present a socially acceptable identity, develop a sense of selfworth, and have a positive future outlook. However, it encouraged social isolation and withdrawal.

\section{Discussion}

This study is the first to explore in-depth how adolescents living with SCD experienced and managed fatigue. The study was conducted in two SCD clinics in Ghana. Fatigue was a common symptom and an everyday experience for all the adolescents who participated in the study. Fatigue was closely linked to the young people's everyday activities and the sociocultural expectations tied to their daily activities. Energy was synonymous to the participants' fatigue experiences, which is captured by the theory as a daily process of energy loss and energy management. The adolescents' energy management strategies (energy restoration, conservation and diversion) are similar to the cancer-related fatigue prevention strategies (energy saving, energy expending and energy generating) highlighted among adults with lung and colon cancer. (Olson et al., 2002), as well as the 'facing outward' and 'facing inward' approaches employed by adults with major depressive disorder to manage their fatigue and its consequences (Porr, Olson \& Hegadoren, 2010). 
Based on the current findings, the experience of fatigue influenced how the adolescents made sense of the relationship between the body, self, SCD and society, and how it forced them to make compromises and employ novel strategies. The sociocultural assumptions and expectations of an adolescent or a youthful body were intricately tied to the adolescents' experiences and how they constructed their bodies and fatigue. They did not challenge the social assumptions about youthfulness and physicality but internalized them as a more or less natural and fixed set of norms and expectations and tried to reproduce them, which is consistent with Bourdieu's $(1990,1997)$ concept of 'habitus'. Although it has been argued that people are not necessarily aware that social structures and norms construct their life (Edward \& Imrie, 2003), fatigue emerged as the SCD symptom that significantly challenged the adolescents' ability to conform to socio-cultural expectations, making the social assumptions about a young person's physicality visible to them. Fatigue gave meaning and significance to these assumptions in the lives of the adolescents, and the assumptions provided them with a framework within which to make sense of their fatigue and social context, giving meaning and significance to fatigue, as argued in the literature on disability (Edward \& Imrie, 2003). This is an important finding because it reveals the interaction between fatigue and socio-cultural assumptions and expectations, as well as how the socially constructed expectations of the physical body influence illness experiences.

The study suggests fatigue as the most restrictive and disruptive aspect of SCD. The meaning and significance of fatigue lay in what it symbolized. Fatigue represented a socially undesirable feature, which marked the adolescents out as different, making it difficult for them to construct and maintain expected and preferred identities. Because fatigue was embodied, it appeared to be a permanent feature of their sense of self and identity. Fatigue led to a daily conscious awareness of a dysfunctional body, which is deficient and ineffective. This made it difficult for the adolescents to separate if from their identities to construct 
normalcy. This is contrary to SCD-related pain which being time-bound and temporal may not permanently affect self and identity. Therefore, fatigue might be the feature of SCD that has the most profound salience to adolescents' social and self-identity development, possibly playing a significant role in the reported poor self-concept reported in adolescents with SCD (Poku et al., 2018).

The research findings also suggest fatigue is a symbolic site for daily struggle, despair and strategy as the adolescents tried daily to assert their claims to 'normality' and to construct and maintain positive identities. Fatigue was the aspect of SCD that exposed them to social and felt stigma (Link \& Phelan, 2001), and significantly influenced their social interactions and sense of 'normality'. SCD invisibility meant that fatigue was the symptom that predisposed the study participants to stigma. They experienced stigma and discrimination when their fatigue became visible during physical activity. This fits with Goffman's (1968) concept of discreditable stigma. Fatigue also led to the construction of negative selfnarratives or the endorsement of derogatory labels, leading to felt stigma (Millen \& Walker, 2001). Hence, while fatigue may not be immediately apparent to others, it is very real to adolescents, and they expected to be stigmatized by others when it becomes discernible. The felt stigma fatigue evoked put the adolescents on constant guard to manage information and impression because visibility is a key feature of identity markers, and stigmatization is increased if the signs and symptoms of a condition are visible to others (Goffman, 1968; Charmaz, 1999; Millen \& Walker, 2001). According to Charmaz (1999), a visible stigma has the potential to become a master status, subsuming other positions as well as becoming a master identity overriding every other identity. Thus, fatigue has the potential to override any other positive identity or status adolescents with SCD may construct.

Consequently, the most important issue for the adolescents was that fatigue remained outside of their social identities and invisible to others. They were therefore constantly 
seeking to hide or reduce their fatigue, and physical incapacitates by adopting strategies, generically called 'passing' by Goffman (1968), to manage, control and cover-up fatigue to protect themselves from anticipated and enacted stigma (Link \& Phelan, 2001). The use of passing and information and impression management has been highlighted in young people with chronic illness such as asthma and diabetes, where concealment is possible (Miller, Willis \& Wyn, 1993; Williams, 2000; Balfe, 2007, 2009; Lambert, 2015). Similar findings have also been reported among adults with major depressive disorder, who have been described to 'put on a mask' to disguise their fatigue (Porr et al., 2010). Felt stigma, therefore, appeared to be more pervasive than the actual stigma the adolescents experienced. These findings are significant because they are the first to suggest fatigue as a stigmatized attribute in relation to long-term conditions.

Deliberate social isolation and withdrawal was a strategy the adolescents commonly employed to manage information and impression to pass as 'normal', and they seemed to use their constructed negative self-narratives to justify this social exclusion (Millen \& Walker, 2001). This approach to managing fatigue in order to maintain positive social identity is in line with Porr et al.'s (2010) concept of 'facing inward'. According to them, adults with major depressive disorder withdraw socially when they are not able to' hold up the mask' of concealing their fatigue from others. Indeed, while social isolation and withdrawal has been commonly identified in the literature about the experiences of adolescents with SCD and adults with depression as a direct negative consequence of the conditions (Porr et al., 2010; Poku et al., 2018), it is a strategy purposively used by adolescents with SCD and adults with major depression disorder to manage fatigue and it seems to be successful in helping them to renegotiate social repsonsibilities in order to preserve/restore energy and maintain positive social identities. Thus, in young people SCD, social isolation and withdrawal may not necessarily indicate emotional or mental health problems. This might explain the discrepancy 
between the reported higher prevalence of depressive and anxiety symptoms when using standardized measurement tools, and the clinically insignificant prevalence rate from detailed psychiatric assessment (Poku et al., 2018).

The research findings indicated that the adolescents attempted to create new social selves/identities to salvage creditable social self/ identity (Goffman, 1968). They used strategies such as 'playing to their strengths' and pursuing intellectual excellence to promote purposive negotiation of positive identities shared within their social domains, finding new confidence in challenging fatigue and its associated stigma, as asserted in the literature (Millen \& Walker, 2001). This extends the literature on the normalization strategies employed by young people with long-term conditions. Most of the reported evidence highlights young people with SCD and other long-term conditions striving for a life and identities like that of their healthy peers (Taylor, Gibson \& Franck, 2008; Poku et al., 2018). However, this study highlights that the adolescents were aware of their inability to construct identities similar to those of their peers due to the fatigue they experienced. Therefore, some of them were pursuing alternative identities that they perceived were equally valued and accepted in their social domains to distance themselves from stigma. This normalisation strategy has the potential to create avenues/opportunities for supporting young people living with SCD - and potentially other long-term conditions - to normalise their lives positively and at the same time maintain their health.

The 'body as a machine' concept was central in the adolescents' fatigue experiences. While the construct has been criticized as a biomedical model which represent the body in a dualistic and reductionist way as opposed to the body as a phenomenological, emotional and a lived entity, which is socially constructed (Lawton, 2003; Shilling, 2003), for participants in this study, the image captured the SCD body as physical/biological, social, symbolic and experiential. The image helped the adolescents to capture the diminished capacities of their 
physical bodies and to construct their identities and social value and positions. It showed how the concepts of self and identity are constructed through the physical body itself. It represented the fatigue experienced by them both as a product of biological deficiency and a result of sociocultural disadvantage, integrating the social with the personal by highlighting the interrelationships between the biological body and sociocultural contexts (Kelly \& Field, 1996).

According to them, the 'body as a machine' image represented the symbolic value of an adolescent/youthful body. Consequently, the SCD body, which the adolescents constructed as a machine with limited energy capacity and highly susceptible to fatigue, was negatively valued by them and others. They therefore tried to reproduce what constituted socially valued physicality congruent to their age and gender, highlighting the reported interplay of disability, bodies and socio-cultural environments in mediating identities and social positions (Bourdieu, 1989; Kelly \& Field, 1996; Edwards \& Imrie, 2003; McLaughlin \& Coleman-Fountain, 2014; McLaughlin, 2017). This is not unique to the adolescents involved in the study because the image has been grounded in several lay accounts of health and illness, regarding normality, self and identity in the context of body maintenance, discipline and technological 'fixes' in young people with cerebral palsy, asthma and diabetes; and in physical education, sports, masculinity, infertility and hormonal contraception (Miller et al., 1993; Kirk \& Tinning, 1998; Williams, 2000; Murray, 2003; Gill, Henwood \& McLean, 2005; Clarke \& Martin-Matthews, 2006; Balfe, 2007, 2009; McLaughlin \& Coleman-Fountain, 2014; Monaghan \& Gabe, 2015; 2016; McLaughlin, 2017). The study findings appear to support the arguments that the image of the body is pivotal in the construction and maintenance of self and social identities (Kelly \& Field, 1996; Williams, 2003). 
The adolescents were actively using strategies to manage the SCD body to construct socially acceptable identities, which Shilling's (2003) refer to as 'body project'. They were actively involved in body projects intended to produce normal identities unaffected by fatigue. They defined themselves through their bodies and were mostly concerned with their outward bodily performance rather than their appearance. They appeared to be involved in a 'normal body' project oriented towards the present (i.e. a 'normal' adolescent body) and the future (i.e. a 'normal' adult body). Adolescents with asthma, diabetes, cerebral palsy and Duchenne muscular dystrophy have been reported to engage in body projects to construct identities that were oriented towards social image (Williams, 2000; Balfe, 2007; 2009; Gibson, 2007, 2009; McLaughlin \& Coleman-Fountain, 2014; Monaghan \& Gabe, 2015, 2016; McLaughlin, 2017). This indicates the temporality of the symbolic meaning of the material body as a young person grows and transition into adulthood, which concurs with Shilling's (2003) concept of the body as 'unfinished' at birth which individuals attempt to complete through bodyworks.

The energy management strategies employed by the adolescents represented the bodyworks they employed in order to work towards 'finishing' the SCD body. These body projects and bodyworks highlight the safety of 'normality', and the importance of the social contexts of adolescence and adulthood to the relationship young people with SCD have with their bodies. Similar findings have been reported in adolescents with cystic fibrosis, cerebral palsy and Duchenne muscular dystrophy (Gibson et al., 2007; Gibson, Zitzelsberger \& McKeever, 2009; Moola \& Norman, 2011; McLaughlin \& Coleman-Fountain, 2014; McLaughlin, 2017). These findings highlight the significance of the dominant constructions of normality in adulthood to young people. Consequently, self-management support and interventions for young people need to be future-oriented, helping them to work towards their desired future outcomes. This has the potential to promote positive attitudes towards self- 
management practices, which has been reported as negative among adolescents with longterm conditions (Atkin \& Ahmad, 2000; Taylor et al., 2008; Poku et al., 2018).

\section{Limitations}

The study has some limitations. First, the findings must be considered in light of their being from a sample recruited from two sickle cell centers in Ghana from 2016 to 2017. The views reported are therefore solely from adolescents who were registered and actively accessed care at these centers. Moreover, recruitment of participants to the study was under the direct control of the health professionals at the research settings, which may have introduced intentional or unintentional selection bias. Furthermore, although efforts were made to ensure no meaning was lost in translating interviews conducted in Twi to English, this could still be a limitation for this research. Lastly, the research findings are based on the analysis and interpretations of adolescents' accounts that were generated by the researchers. The views, ideas, knowledge, interactions, backgrounds and assumptions of the researchers (a mixture of clinical and nonclinical expertise, with knowledge of methods and clinical research in the chronic illness field and researching with children) therefore partly shaped the research process and subsequently the research outcomes (Charmaz, 2014; Mason, 2017).

\section{Conclusion}

With this study, we contribute to knowledge by exploring and presenting in-depth, for the first time, the fatigue experiences of adolescents with SCD. The study reveals fatigue as a stigmatized attribute and a major daily threat to normalcy. This is where the significance and meaning of fatigue to the adolescents' lives laid. Therefore, managing fatigue to construct and maintain socially acceptable identity dominates adolescents with SCD lives and informs their day-to-day pursuits. This suggests more attention needs to be given to fatigue, both to 
the challenges it presents and to how adolescents manage it. The study highlights the adolescents' active and creative capacities to shape their lives through diverse selfmanagement strategies. This highlights the importance of young people with SCD not only being actively involved in their own care but also in developing appropriate policies, practices and interventions. However, implementation of this approach in non-Western contexts, like Ghana, present challenges as children usually have no power to participate, make meaningful contributions and influence decisions about their lives (Adu-Gyamfi, 2014), despite the UN charter on the rights of the child. The study also highlights the significance of the physical body and its capacities in the interpretations and attribution of meanings by young people to their illness experiences. Hence, research focusing on the physicality of the body could prove a more holistic way of understanding illness experiences. 


\section{References}

Abrams, L. S., Curran, L. (2011) Maternal identity negotiation among low-income women with symptoms of postpartum depression. Qualitative Health Research, 21: 375-385. doi: $10.1177 / 1049732310385123$

Adu-Gyamfi, J. (2014) Childhood construction and its implications for children's participation in Ghana. African. Journal of Social Sciences, 4(2): 1-11. Available at: https://www.researchgate.net/publication/277585700 [accessed 15/05/16]

Ameringer, S., Elswick, R. K., Smith, W. (2014) Fatigue in adolescents and young adults with sickle cell disease: Biological and behavioral correlates and health-related quality of life. Journal of Pediatric Oncology Nursing, 31(1): 6-17. doi: 10.1177/1043454213514632

Amr, M. A., Amin, T. T., Al-Omair, O. (2011) Health-related quality of life among adolescents with sickle cell disease in Saudi Arabia. PanAfrican Medical. Journal, 8(10). doi: 10.4314/pamj.v8i1.71057

Anderson, L.M., Allen, T.M., Thornburg, C. D., Bonner, M. J. (2015) Fatigue in children with sickle cell disease: Association with neurocognitive and socio-emotional functioning and quality of life. Journal of Pediatric Hematology and Oncology, 37(8): 584-589. doi: 10.1097/MPH.0000000000000431

Atkin, K., Ahmad, W. I. U. (2000) Pumping iron: Compliance with chelation therapy among young people who have thalassaemia major. Sociology of Health and Illness, 22(4): 500-524. doi: $10.1111 / 1467-9566.00216$

Balfe, M. (2007) Diets and discipline: The narratives of practice of university students with type 1 diabetes. Sociology of Health and Illness, 29(1): 136-153. doi: 10.1111/j.14679566.2007.00476.x

Balfe, M. (2009) The body projects of university students with type 1 diabetes. Qualitative Health Research, 19(1): 128-139. doi: 10.1177/1049732308328052 
Birks, M., Mills, J. (2015) Grounded theory: A practical guide (2 ${ }^{\text {nd }}$ ed.). London: SAGE Publications.

Bourdieu, P. (1989) Social space and symbolic power. Sociological Theory, 7(1): 14-25. Available at: https://www.jstor.org/stable/pdf/202060.pdf?refreqid=excelsior\%3Aecd07293cf290f351c928 c59edc2c669 [accessed 10/10/2018]

Boakye-Boaten, A. (2010) Changes in the concept of childhood: Implications on children in Ghana. The Journal of International Social Research, 3(10): 304-115. Available at: https://www.researchgate.net/publication/277585700 [accessed 15/05/16]

Chant, S., Jones, G. A. (2005) Youth, gender and livelihoods in West Africa: Perspectives from Ghana and the Gambia. Children Geographies, 3(2): 185-199. doi: $10.1080 / 14733280500161602$

Charmaz, K. (2014) Constructing grounded theory. London: SAGE Publications

Charmaz, K. (1999) From the sick role to stories of self. In: Contrada R. J. \& Ashmore, R. D. (Eds.) Self, social identity and physical health. Oxford: Oxford University Press

Clarke, L. H., Martin Matthews, A. (2006) The continuity and discontinuity of the embodied self in infertility. Canadian Review of Sociology, 43(1):95-113. doi: 10.1111/j.1755618X.2006.tb00856.x

Dampier, C., Lieff, S., LeBeau, P., Rhee, S., McMurray, M., Rogers, Z., Smith-Whitley, K., Wang, W. (2010) Health-related quality of life in children with sickle cell disease: A report from the comprehensive sickle cell centers clinical care consortium. Pediatric Blood Cancer, 55: 485494. doi: $10.1002 / p b c .22497$

Dennis-Antwi, J., Culley, L., Hiles, D. R., Dyson, S. M. (2011) 'I can die today, I can die tomorrow': Lay perceptions of sickle cell disease in Kumasi, Ghana at a point of transition. Ethnicity and Health, 16(4-5): 465-481. doi: 10.1080/13557858.2010.531249 
Dormandy, E., James, J., Baba I., Rees, D. (2018) How many people have sickle cell disease in the UK? Journal of Public Health, 40(3): e291-e295. doi: 10.1093/pubmed/fdx172

Edwards, C., Imrie, R. (2003) Disability and bodies as bearers of value. Sociology, 37(2): 239-256. doi: $10.1177 / 0038038503037002002$

Epstein, D. (1998) 'Are you a girl or you are a teacher?' The least adult role in research about gender and sexuality in primary school. In: Galagher (ed.) Doing research about education, pp. 2741. London: Falmer

Gibson, B. E., Young, N. L., Upshur, R. E. G., McKeever, P. (2007) Men on the margin: A Bourdieusian examination of living into adulthood with muscular dystrophy. Social Science and Medicine, 65: 505-517. doi: 10.1016/j.socscimed.2007.03.043

Gibson, E. B., Zitzelsberger, H., McKeever, P. (2009) 'Futureless person': Shifting life expectancies and the vicissitudes of progressive illness. Sociology of Health and Illness, 31(4): 554-568. doi: 10.1111/j.1467-9566.2008.01151.x

Gill, R., Henwood, K., McLean, C. (2005) Body projects and the regulation of normative masculinity. Body \& Society, 11(1): 37-62. doi: 10.1177/1357034X05049849

Goffman, E. (1968). Stigma: Notes on the management of a spoiled identity. Harmondsworth, UK: Pelican Books (Original work published in 1963).

Hall, W. A., Callery, P. (2001) Enhancing the rigor of grounded theory: Incorporating reflexivity and relationality. Qualitative Health Research, 11(2): 257-272. doi: $10.1177 / 104973201129119082$

Keller, M., Ding, S. (2004) Middle childhood. In: Fraser, S., Lewis, V., Ding, M. et al. (Eds.) Doing research with children and young people, pp. 161-174 London: The Open University.

Kelly, M. P., Field, D. (1996) Medical sociology, chronic illness and the body. Sociology of Health and Illness, 45: 254-278. doi: 10.1111/1467-9566.ep10934993 
Kirk, D., Tinning, R. (1994) Embodied self-identity, healthy lifestyles and school physical education. Sociology of Health and Illness, 16(5): 600-625. doi: 10.1111/1467-9566.ep11348096

Laird, Y., Fawkner, S., Niven, A. (2018) A grounded theory of how social support influences physical activity in adolescent girls. International Journal of Qualitative Studies on Health and Well-being, 13(1). doi: 10.1080/17482631.2018.1435099

Lambert, V. (2015) Striving to live a normal life: A review of children and young people's experience of feeling different when living with a long term condition. Journal of Pediatric Nursing 30: 63-77. doi: 10.1016/j.pedn.2014.09.016

Lawton, J. (2003) Lay experiences of health and illness: Past research and future agenda. Sociology of Health Illness, 25: 23-40. doi: 10.1111/1467-9566.00338

Link B. G., Phelan, J. O. (2001) Conceptualizing stigma. Annual Review of Sociology, 27: 363-385. doi: 10.1146/annurev.soc.27.1.363

Markham, A. (2017) Reflexivity: some techniques for interpretive researchers [Online]. Available at: https://annettemarkham.com/2017/02/reflexivity-for-interpretive-researchers/ [accessed $15 / 08 / 17]$

Mason, J. (2017) Qualitative researching (3 ${ }^{\text {rd }}$ ed.). London: SAGE Publications

McLaughlin, J. (2017) The medical reshaping of disabled bodies as a response to stigma and a route to normality. Medical Humanities, 43: 244-250. doi: 10.1136/medhum-2016-011065

McLaughlin, J., Coleman-Fountain, E. (2014) The unfinished body: The medical and social reshaping of disabled young bodies. Social Science and Medicine, 120: 76-84. doi: 10.1016/j.socscimed.2014.09.012

Millen, N., Walker, C. (2001) Overcoming the stigma of chronic illness: Strategies for normalisation of a 'spoiled identity'. Health Sociology Review, 10(2): 89-97. doi: 10.5172/hesr.2001.10.2.89 
Miller, R., Willis, E., Wyn, J. (1993) Gender and compliance in the management of a medical regimen for young people with cystic fibrosis. Paper presented at BSA Medical Sociology Conference, University of York, UK

Monaghan, L. F., Gabe, J. (2015) Chronic illness as a biographical contingency? Young people's experiences of asthma. Sociology of Health and Illness, 37, 1236-1253. Doi: 10.1111/14679566.12301

Monaghan, L. F., Gabe, J. (2016) Embodying health identities: A study of young people with asthma. Social Science and Medicine, 160: 1-8. doi: 10.1016/j.socscimed.2016.05.013

Moola, F. L., Norman, M. E. (2011) 'Down the rabbit hole': Enhancing the transition process for youth with cystic fibrosis and congenital heart disease by re-imaging the future and time. Child: Care, Health and Development, 37(6): 841-851. doi: 10.1111/j.13652214.2011.01317.x

Moore, T., McArthur, M., Noble-Carr, D. (2008) Little voices and big ideas: Lessons learned from children about research. International Journal of Qualitative Methods, 7(2): 77-91. doi: $10.1177 / 160940690800700205$

Mulumba, L., Wilson, L. (2015) Sickle cell disease among children in Africa: An integrative literature review and global recommendations. International. Journal of Africa Nursing Sciences, 3: 56-64. doi: 10.1016/j.ijans.2015.08.002

Murray, D. (2003) The meaning of boys' bodies in physical education. Journal of Men's Studies, 11(2): 131-141. doi: 10.3149/jms.1102.131

National Heart, Lung and Blood Institute (2009) who is at risk for sickle cell anemia? Available at: http://www.nhlbi.nih.gov/health/dci/Diseases/Sca/SCA_WhoIsAtRisk.html [accessed 01/02/20]

- Ohene-Frempong, K., Oduro, J., Tetteh, H., Nkrumah, F. K. (2008) Screening newborns for sickle cell disease in Ghana. Pediatrics, 121 (2). doi: 10.1542/peds.2007-2022UUU 
Olson, K., Tom, B., Hewitt, J., Whittingham, J., Buchanan, L. Ganton, G. (2002) Evolving routines: Managing fatigue associated with lung and colorectal cancer. Qualitative Health Research, 12 (5): 655-670. doi: 10.1177/104973202129120160

Panepinto, J. A., Torres, S., Bendo, C. B., McCavit, T. L., Dinu, B., Sherman-Bien, S., BemrichStolz, C., Varni, J. W. (2014) PedsQL ${ }^{\mathrm{TM}}$ multidimensional fatigue scale in sickle cell disease: Feasibility, reliability and validity. Pediatric Blood Cancer, 61(1): 171-177. doi: 10.1002/pbc. 24776

Piel, F. B., Hay, S. I., Gupta, S., Weatherall, D.J., Williams, T. N. (2013) Global burden of sickle cell anaemia in children under five, 2010-2050: Modelling based on demographics, excess mortality and interventions. PLoS Med, 10(7), e1001404. doi: 10.1371/journal.pmed.1001484

Poku, B. A., Caress, A-L., Kirk, S. (2018) Adolescents' experiences of living with sickle cell disease: An integrative narrative review of the literature. International Journal of Nursing Studies, 88: 20-28. doi: 10.1016/j.ijnurstu.2017.12.008

Poku, B. A., Caress, A-L., Kirk, S. (2019) Opportunities and challenges of using phot-elicitation in child-centered constructivist grounded theory research. International Journal of Qualitative Methods, 18: 1-7. doi: 10.1177/1609406919851627

Porr, C., Olson, K., Hegadoren, K. (2010) Tiredness, fatigue and exhaustion in the context of a major depressive disorder. Qualitative Health Research 20, 1315-1326. doi: $10.1177 / 1049732310370841$

Rogers, V. E., Lance, E. I. (2017) Sleep, fatigue and neurodevelopmental outcomes in pediatric sickle cell disease. Austin Pediatrics, 4(2). doi: ajp-v4-id1056.php

Salm, S. J., Falola, T. (2002) Culture and Customs of Ghana. Greenwood Press: Connecticut Shilling, C. (2003) The body and social theory ( $2^{\text {nd }}$ ed.). Thousand Oaks, CA: SAGE 
Taylor, R. M., Gibson, F., Franck, L. S. (2008) The experience of living with a chronic illness during adolescence: A critical review of the literature. Journal of Clinical Nursing 17: 3083-3091. doi: 10.1111/j.1365-2702.2008.02629.x

While, A. E., Mullen, J. (2004) Living with sickle cell disease: The perspectives of young people. British Journal of Nursing, 13(6): 320-325. doi: 10.12968/bjon.2004.13.6.12528

Williams, C. (2000) Doing health, doing gender: Teenagers, diabetes and asthma. Social Science and Medicine, 50: 387-396. doi: 10.1016/S0277-9536(99)00340-8

Williams, S. J. (2003) Medicine and the body. London: SAGE 